\title{
The use of methods of structural optimization at the stage of designing high-rise buildings with steel construction
}

\author{
Andrey Vasilkin ${ }^{1, *}$ \\ ${ }^{1}$ Moscow State University of Civil Engineering; 26, Yaroslavskoe Shosse, Moscow, 129337, Russia
}

\begin{abstract}
The more designing solutions at the search stage for design for high-rise buildings can be synthesized by the engineer, the more likely that the final adopted version will be the most efficient and economical. However, in modern market conditions, taking into account the complexity and responsibility of high-rise buildings the designer does not have the necessary time to develop, analyze and compare any significant number of options. To solve this problem, it is expedient to use the high potential of computer-aided designing. To implement automated search for design solutions, it is proposed to develop the computing facilities, the application of which will significantly increase the productivity of the designer and reduce the complexity of designing. Methods of structural and parametric optimization have been adopted as the basis of the computing facilities. Their efficiency in the synthesis of design solutions is shown, also the schemes, that illustrate and explain the introduction of structural optimization in the traditional design of steel frames, are constructed. To solve the problem of synthesis and comparison of design solutions for steel frames, it is proposed to develop the computing facilities that significantly reduces the complexity of search designing and based on the use of methods of structural and parametric optimization.
\end{abstract}

\section{Introduction}

One of the orientation of development of computer-aided design systems is the automation of the process of searching for design solutions [1]. Traditionally, it is believed, that the design process cannot be automated because the search and adoption for design solutions is one of the creative tasks of a design engineer, whose decision is largely based on intuition and experience [2]. At the same time, it is possible to identify formally solvable procedures, the implementation of which by means of information technology allows to solve a number of design tasks automated [3].

Such problems include the task of finding a set of variable parameters of project solutions that satisfy specified criteria and constraints [4]. One of the methods of searching parameters in the decision space, which is widely used in the design, is the nonlinear programming $[5,6,7]$. However, in the practice of building high-rise buildings connected

\footnotetext{
*Corresponding author: vergiz@mail.ru
} 
with the discrete nature of the variable parameters and the complexity of formalizing the objective function, the use of nonlinear programming is rare, since it requires engineers to have a deep knowledge of optimization theory.

\section{Methods}

Methodologically, the task of searching for design solutions in the design of high-rise buildings can be considered as a combination of two main tasks: the synthesis of the structure of the design object and the synthesis of the parameters of the design object- the choice of the numerical values of the variable parameters of the structural elements.

To obtain an effective solution, this methodology should be based on a wide use of the capabilities of modern information technologies and optimization methods [8]. The methodology is based on the use of computing methods of search on simulation models of buildings, application of the principles of decomposition of complex models and organization of the system design process. In search designing, the engineer must simultaneously take into account the various design goals and requirements for the design, both possible in quantitative terms and those that cannot be expressed quantitatively, for example the architectural expression that is particularly relevant for high-rise buildings [9]. Many of these goals and requirements may contradict each other, suggesting the need for a decision by the engineer.

To make the frame better in general, the optimization technique should help the engineer to manage increasingly complex building projects, enabling the synthesis of several design options. Taking into account the possibilities of modern software, the use of computing methods in the field of structural and parametric optimization of engineering and architectural designing allows for in-depth analysis and extends the range of the analyzed high-rise buildings in the initial stages of designing, since it increases the speed of search and acceptance of project solutions, taking into account the variability of impacts on the subsequent stages of the life cycle of the structure. These tasks are solved successfully during the synthesis of the topology of structural coverage [10], structural constructions [11], the search for the building layout [4].

Structural and parametric optimization is the methodology that helps to solve the tasks, to meet the needs of engineers and to direct the vector of solutions in alternative design. Structural and parametric optimization is widely used in machine building [12,], aircraft construction [14], algorithms for solving problems and practical tasks in construction have been developed $[15,16]$; there are examples of carrying out structural optimization in search conceptual design [11]. Nevertheless, for complex tasks with a large number of variable parameters, which include the construction of high-rise buildings, modern design tools lack functionality to ensure wide use of optimization methods. Also, most optimization algorithms focus more on solving purely engineering problems than on constructive design synthesis and search design $[17,18]$. Often, the ability of engineers to synthesize a structure is limited to insufficiently effective feedback, which affects the search for a solution. As a result, such an effective and powerful method as structural and parametric optimization, which allows to significantly reduce the cost and complexity of designing, is used in insufficient capacity in the design process.

\section{Results}

Thus, there is a need for a study aimed at increasing the availability, ease of use and flexibility of optimization processes to assist engineers in finding effective design solutions in the early stages of designing high-rise structures. 
Many domestic and foreign researchers have made a large initial contribution to the methods of parametric and structural optimization $[19,20]$. Such works as the study in the field of numerical optimization [19], the use of the genetic algorithm [21,22,23] are included in the list. Although these studies point to the enormous potential for structural and parametric optimization being used in the field of design, quite a few studies pay attention to the possibilities of interactive application of optimization methods for solving problems and achieving development goals, which are used by engineers. Also, many current computing devices require complicated preliminary preparation and manipulation, long- time setup, as well as complicated transfer of information between different programs, which reduces the possibility of their application in practice.

The above tasks can be accomplished using information technology supporting search for design solutions, within which the application of evolutionary principles of multipurpose parametric optimization with complex objective functions is realized [1]. This subsystem includes such functions as finding compromises, providing a variety of solutions, correcting the design goal while searching for solutions, visualizing and exporting results, which allows to synthesize optimal designs in the process of search design. The integration of such systems with the using of CAD (computer-aided)-programs in designing is especially effective when relying on the functionality of existing tools [24, 25].

Structural optimization at the stage of search design. This article describes the application of structural and parametric optimization methods, as well as approaches to their integration into the process of searching for design solutions at the stage of variant design of high-rise buildings. The structure of the projected object is a specific system that describes the totality of the composite elements and the relationships between them. A complete set of elements defining a design object can be represented as an imitation model of an object. Depending on the designing stage, the degree of specification and the working at the designing solution, the simulation model can reflect the various characteristics of the designed object [26]. Description of the simulation model can take different forms, it can be a mathematical dependence, a draft or information (numerical) model.

It is efficiently to select the rational structure of the design object is with the help of structural synthesis. Each structure has a set of parameters that the engineer can accept as variable or constant. The choise of numerical values of the set of variable parameters, for example steel class, section type, section size, etc. is the problem of parametric synthesis. The methodology for finding the structure of the design object is shown in Fig. 1.

When the structure is formed, the designer deals with formally undefined structural relationships and qualitative criteria, therefore at this stage, the formation of the initial structure is carried out taking into account the informal description of the projected object [19].

One of the main principles embodied in most optimization methods is the use of a model that simulates a real design object and organization of a design cycle for it. The process of computer-aided design is based on using the model as a means of analysis and selection procedure of the parameters as a means of automated solution search. In general, the computer-aided design system can have various means for forming a structure and selecting parameters, depending on the design stage, that is, the designer's goals. 


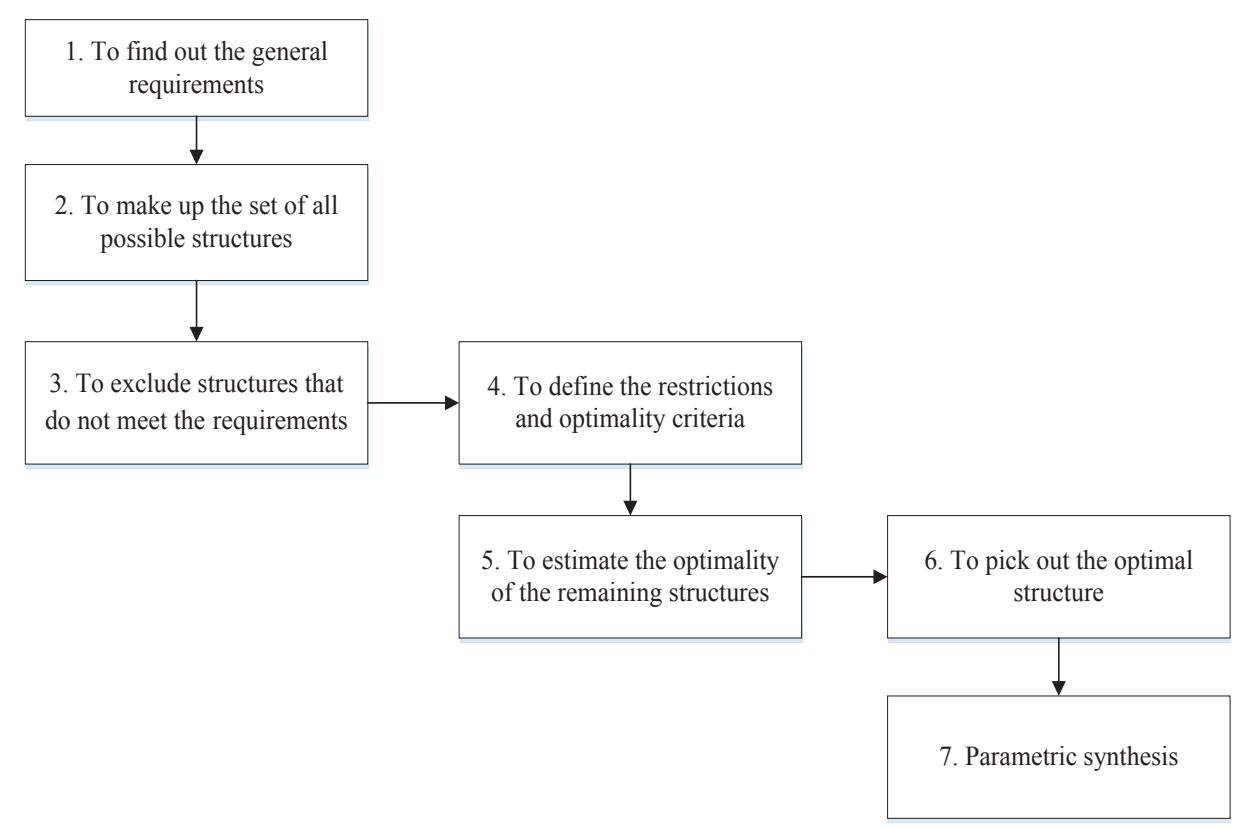

Fig. 1. The methodology of choice of the structure of the design object.

It is necessary to develop a software tool that is automated to search for the optimal structure of the designed object for practical application of the structural optimization method. It is obvious that today an engineer in many ways independently makes decisions, but at the same time it is possible to identify formalized procedures that can be represented in the form of an algorithm. In the future, when solving such problems, it is logical to expect the increasing application of $\mathrm{CAD}$, which is associated with the development of computing technologies and capacities.

The initial data for the design of the object is a technical task that contains an indication of the functional purpose of the object, operating conditions (construction area, technological impacts), process technology for industrial buildings, and the environment description. in which the functioning and designing of the object is carried out in the form of a set of non-variable parameters, which can't be changed by the engineer. Analyzing the technical task the engineer, based of his experience, sets the criteria for the synthesis of the design solution and the imposed restrictions.

The following stages describe the operation of the software model in the synthesis of the designed object structure.

In the developed computing facility, a database is created that contains a group of design objects (beams, industrial buildings, steel-plate constructions, high-rise constructions, etc.) and for each group a list of possible structures and elements is given.

Stage 1. The download manager leaves the list of elements of the projected system from the database to the user's choice.

Stage 2. The user selects a specific element from the list for his designed object.

Stage 3. The user sets the threshold values of the corresponding variables.

Stage 4 . The computing means calculates by the embedded algorithm and presents to the user the possible values of the variable parameters of the structure of the object, taking into account the restrictions associated with the shipping clearances, the possibility of manufacturing and assemblage, the peculiarities of operating conditions, etc.

At the last stage, the user specify the optimality criterion, based on which the selects the optimal solution of all the variants proposed by the software. This criterion is a set of 
output functions of the simulation model and the corresponding restrictions in the form of numerical or qualitative values, which must be met by these figures. One of these functions can be adopted as the target when optimizing. In this case, in the process of synthesis, this function must reach an extremum - a maximum or a minimum.

Stage 5. Then the structure sequentially varies among a visible number of possible variants of its implementation, the procedures of parametric synthesis are realized for each structure. Variants of the structure can be set by the user and thus have a rather small spectrum, or be synthesized using a genetic algorithm.

Consideration of the presented design methodology allows us to present the process of designing steel constructions in the form of a generalized scheme that is invariant to design objects (Fig. 2).

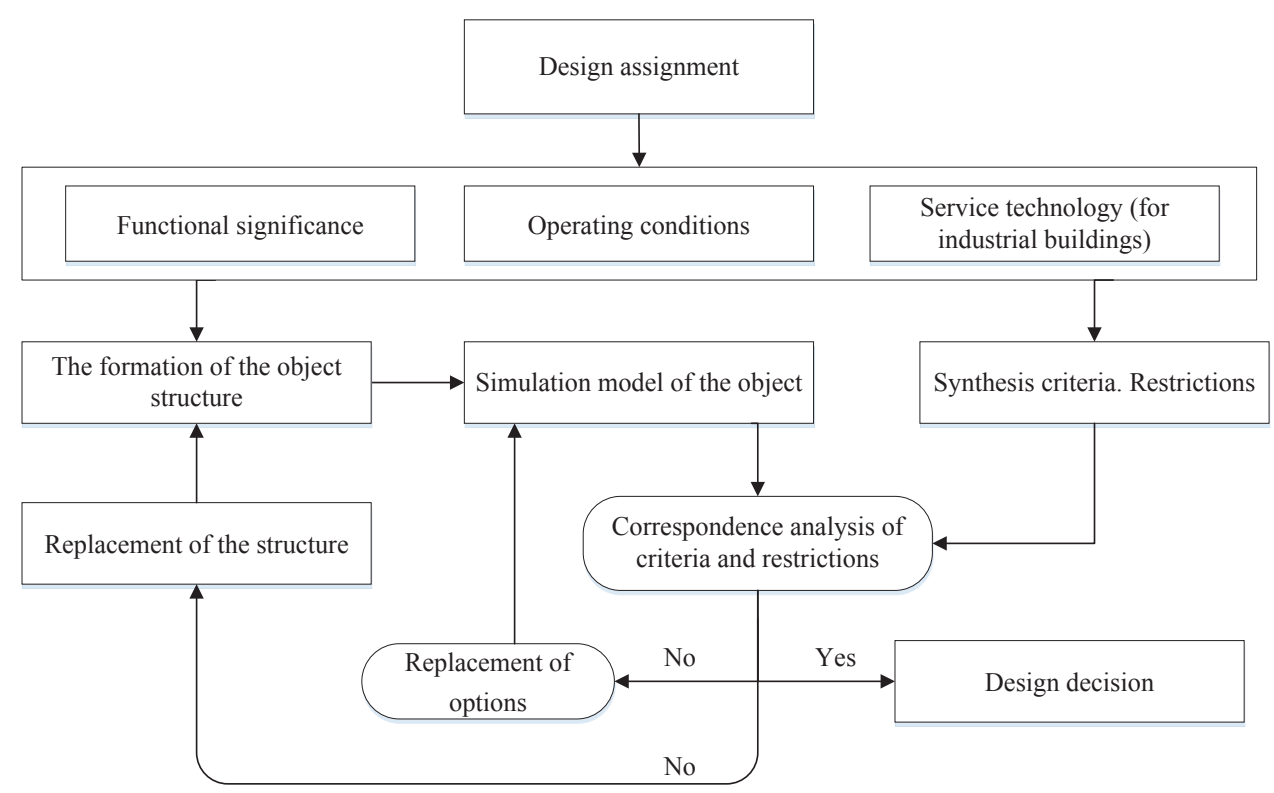

Fig. 2. Generalized design scheme.

Thus, the design process can be viewed as a set of two iterative cycles: the formation and modification of the structure and the exhaustive search of parameters. In parametric synthesis, it is assumed that the structure of the designed system and its simulation model has already been determined, the parameters of the elements have a metric expression.

It is difficult to synthesize the structure, as the engineer has to figure out which parameter and within what limits it will be changed. It is necessary to find out such a parameter in order it will be possible for the synthesized structures differ from each other, the range of possible solutions is wider and then it is hoped that the more the number of variants can be synthesized, the more effective one will be

\section{Conclusions}

High-rise buildings consist of a complex of constructions, elements and engineering systems, each of which is subject to an individual designing. In a number of cases, the automation of the structure is possible due to the certainty and homogeneity of the original redundant structure. In a number of cases, the automation of the structure is possible due to the certainty and homogeneity of the original redundant structure [21-26]. The design 
process is of a systemic nature, the main task of which is to check and link the solutions of individual constructions to the setup. In connection with heterogeneity and high dimensionality of search spaces, it is necessary to realize decomposition of a complex task into separate local iterative procedures. At the same time, they are combined into a structure according to certain rules, often these rules are informal, when the knowledge and experience of an engineer are actively used in solving problems of this class.

On the basis of the presented schemes, in the future it is planned to develop a computing means - a software complex, with the help of which the synthesis of project solutions, their visualization and their comparison and analysis is possible. The development of appropriate utilities to the computing means, which was previously developed by the author, can improve the functionality of information technology of supporting search for design solutions. One more important opportunity to increase the productivity of the technique is the use of genetic algorithms to synthesize the structure of the designed object, in this connection the author is currently developing and testing the appropriate tools.

\section{References}

1. A.A. Vasilkin, Promyshlennoe i grazhdanskoe stroitel'stvo, 5, 76-80 (2016)

2. D. Dzhons, Mir, 374 (1976)

3. A.V. Ginzburg, Ya.A. Lobyreva, D.A. Semernin, Nauchnoe obozrenie, 16, 461-464 (2015)

4. A.M. Ibragimov, A.A. Vasilkin, Nauchnoe obozrenie, 13, 32-36 (2016)

5. Edilson F. Arruda, F. Ourique, A. Almudevar, R. C. Silva, American Journal of Operations Research, 3, 431-438 (2013)

6. J. McCall, Journal of Computational and Applied Mathematics, 184, 205-222 (2005)

7. S. Rajeev, C. Krishnamoorthy, J StructEng, 123 (1997)

8. A.A. Volkov, A.A. Vasilkin, Procedia Engineering, 153, 850-855 (2016)

9. M. Maevskaya, Vysotnye zdaniya, 4, 20 - 24 (2016)

10. M.N. Kirsanov, Stroitel'naya mekhanika i raschet sooruzhenii, 2, 60-63 (2010)

11. N.A. Panchukov, Izvestiya vuzov. Stroitel'stvo, 6, 63-73 (2015)

12. D.V. Dmitrienko, Vestnik gosudarstvennogo universiteta morskogo i rechnogo flota im. admirala S.O. Makarova, 3, 655-662 (2017)

13. V.E. Kostin, V.N. Tyshkevich, A.V. Sarazov, A.V. Sin'kov, V.F. Belukha, Mezhdunarodnyi zhurnal eksperimental'nogo obrazovaniya, 4-1, 96-97 (2012)

14. A.P. Erokhin, Novoe slovo $\mathrm{v}$ nauke i praktike: gipotezy i aprobatsiya rezul'tatov issledovanii, 6, 95-99n(2013)

15. I.M. Tumenova, Inzhenernyi vestnik Dona, 2(45), 131 (2017)

16. O.A. Shteinbrekher, T.V. Burnysheva, Inzhenernyi zhurnal: nauka i innovatsii, 10(70) (2017)

17. A.M. Boldyrev, A.A. Svetikov, Metallicheskie konstruktsii, 4, 263-268 (2008)

18. A.G. Tamrazyan, E.A. Filimonova, Sovremennye problemy rascheta zhelezobetonnykh konstruktsii, zdanii i sooruzhenii na avariinye vozdeistviya, 424433 (2016)

19. Y.K. Vermishev, Metody avtomaticheskogo poiska reshenii pri proektirovanii slozhnykh tekhnicheskikh system (Radio i svyaz', Moscow, 1982)

20. D.J. Wilde, Globally optimal design (Wiley, New York, 1978) 
21. D.Yu. Zaporozhets, A.M. Ksalov, I.A. Pshenokova, Informatika, vychislitel'naya tekhnika i inzhenernoe obrazovanie, 1(25), 14-26.(2016)

22. A.P. Karpenko, S.A. Gadzhiev, Sistemy proektirovaniya, tekhnologicheskoi podgotovki proizvodstva i upravleniya etapami zhiznennogo tsikla promyshlennogo produkta, 421-425 (2016)

23. V. Faghihi, K. F. Reinschmidt, J. H. Kang, Expert Systems with Applications, 16, 7565-7578 (2014)

24. N. Brown, J. Ochsendorf, C. Mueller, de Oliveira, Proceedings of the 3rd International Conference on Structures and Architecture, 1103-1111 (2016)

25. N. C. Brown, C. T. Mueller, Energyand Buildings, 127, 748-761 (2016)

26. Yu.V. Sobolev, A.A. Vasil'kin, A.D. Koloskov, Promyshlennoe i grazhdanskoe stroitel'stvo, 12, 44-45 (2005) 